\title{
Websites for critical appraisal in diagnosis and treatment
}

\author{
Clinical Trials and Meta-analysis Unit,
} Universidade Federal de São Paulo/Escola Paulista de Medicina, São Paulo, Brazil

\section{INTRODUCTION}

$\mathrm{K}$ nowing how to critically appraise publications on diagnosis and treatment is an essential skill for a been several publications with this aim. The Internet is revolutionizing the access to information exchange all over the world as it allows microcomputer users to access this information quickly and easily. Of these publications, some of them are available on the Internet without cost, in their entirety, and some with resources that would be impossible to have in the printed version.

Our objective is to highlight some websites which offer tools to facilitate a critical appraisal of the literature and the identification of relevant studies.

\section{WEBSITES}

\section{http://hiru.mcmaster.ca/ebm}

This is located at the site of the Health Information Resources Unit of McMaster University (Canada), and has

\footnotetext{
Address for correspondence:

Aldemar Araújo Castro

Rua Pedro de Toledo 598

São Paulo/SP - Brasil - CEP 04031-001

e-mail: aldemar@iname.com

URL: http://www.geocities.com/Athens/9733
}

the complete text of a series of articles ${ }^{(2-16)}$ published in the Journal of the American Medical Association (JAMA) whose aim is to offer practical tools for critical reading of publications on therapy, diagnosis, prognosis, systematic reviews and other topics, as well as on-line calculators and pre-programmed database search strategies (see PubMed). On accessing the home page, select the item USER'S GUIDE on the left side of the screen, and then the desired item.

\section{http://www.bmj.com/collections/read.htm}

Another series which has been published with the same objective is available at the British Medical Association website. These are excerpts from $\mathrm{T}$. Greenhalgh's book "How to read a paper" (London, BMJ, 1997). The ten articles ${ }^{(17-26)}$ which can be accessed through the above site deal with the Medline database, getting your bearings, assessing the methodological quality of published papers, statistics for the non-statistician, articles about therapeutics, diagnosis and screening tests, economic analyses, systematic reviews and meta-analyses, and papers that go beyond numbers.

\section{http://www.ncbi.nIm.nih.gov/PubMed}

Since September 17th, 1997, the U.S. National Library of Medicine has made the Medline database (Medlares Online) available on the Internet, cost-free to the user. Although some websites which allowed their usage already existed, the direct access to the institution that produces the database is, in my opinion, more reliable. There are three possible access methods: a) basic search; 
b) advanced search; c) clinical queries; d) Journal browser;

e) MeSH browser; f) citation matcher.

Clinical queries, which can be accessed via the left side of the screen, allows you to use a search strategy previously set up for each of the four categories: therapy, diagnosis, etiology and prognosis, automatically. You only have to key in your search theme, choose the category and determine whether the search result is sensible or specific. The strategy used can be observed through the Table item placed at the left side of the screen. The objective of these pre-programmed searches is to identify those articles which offer a good level of evidence.

Understanding how it is organized and what forms of bibliographic database recovery there are, may improve the results of your search. This may be achieved by reading the PubMed Help section and the article written by Lowe. ${ }^{(27)} \mathrm{We}$ also should bear in mind that it is estimated that there are 30,000 biomedical journals in existence: Medline indexes 3,500; Embase (Excerpta Medica Database) indexes 4,000, of which 1,000 are different to those of Medline; Lilacs (LatinAmerican and Caribbean Health Science Literature Database) indexes 670 journals, only 41 of which are indexed by Medline and/or Embase. Due to the individual characteristics of each database, a search whose objective is to review a theme needs to be carried out in all the databases. ${ }^{(28)}$

\section{http://www.epm.br/cochrane}

The Brazilian Cochrane Centre website has available three links of interest: a) abstracts of systematic reviews of the Cochrane Collaboration; b) Free Medline; c) Netting the Evidence; d) SciELO.

- Cochrane Collaboration abstracts are updated quarterly. In the second instalment of the 1998

\section{REFERENCES}

1. Evidence-Based Medicine Working Group. Evidence-based medicine: a new approach to teaching the practice of medicine. JAMA 1992; 268(17):2420-5.

2. Evidence-Based Medicine Working Group. User's guide to the medical literature: I. How to get started. JAMA 1993; 270(17):2093-5.

3. Evidence-Based Medicine Working Group. User's guide to the medical literature: II. How to use an article about therapy or prevention. A. Are the results of the study valid? JAMA 1993; 270(21):2598-601.

4. Evidence-Based Medicine Working Group. User's guide to the medical literature: II. How to use an article about therapy or prevention. B. What were the results and will they help me in caring for my patients? JAMA 1994;271(1):59-63. edition, there are 377 available, all relating to a variety of therapeutic specialities.

- $\quad$ Free MedLine is the access to PubMed.

- $\quad$ Netting the Evidence assembles a list of websites about evidence-based medicine, created and updated by Sheffield University (United Kingdom). An example of the items available is the journal BANDOLIER, which can be accessed via letter B. This journal publishes information on the usage of evidence-based medicine, and articles on diagnosis and treatment, amongst others.

- $\quad$ SciELO (The Scientific Electronic Library Online) is a electronic virtual library covering a selected collection of Brazilian Scientific Journals.

\section{CONCLUSION}

These websites can be extremely worthwhile, and can also serve as an initial guide on how to use the Internet as a source of information for understanding the critical evaluation of medical literature, one of the components of Evidence-Based Medicine.

\section{ACKNOWLEDGMENTS}

The author thanks Dr. Alvaro Atallah and Dr. Otavio Clark for comments that have improved on an earlier version of this paper.

5. Evidence-Based Medicine Working Group. User's guide to the medical literature: III. How to use an article about a diagnostic test. A. Are the results of the study valid? JAMA 1994; 271(5):389-91.

6. Evidence-Based Medicine Working Group. User's guide to the medical literature: III. How to use an article about a diagnostic test. $\mathrm{B}$. What were the results and will they help me in caring for my patients? JAMA 1994;271(9):703-7.

7. Evidence-Based Medicine Working Group. User's guide to the medical literature: IV. How to use an article about harm. JAMA 1994; 271(20):1615-9.

8. Evidence-Based Medicine Working Group. User's guide to the medical literature: V. How to use an article about prognosis. JAMA 1994; 272(3):234-7.

9. Evidence-Based Medicine Working Group. User's guide to the medical literature: VI. How to use an overview. JAMA 1994; 272(17):1367-71. 
10. Evidence-Based Medicine Working Group. User's guide to the medical literature: VII. How to use a clinical decision analysis. A. Are the results of the study valid? JAMA 1995; 273(16):1292-5.

11. Evidence-Based Medicine Working Group. User's guide to the medical literature: VII. How to use a clinical decision analysis. B. What were the results and will they help me in caring for my patients? JAMA 1995; 273(20):1610-3.

12. Evidence-Based Medicine Working Group. User's guide to the medical literature: VIII. How to use clinical practice guidelines. A. Are the recommendations valid? JAMA 1995; 274(7):570-4.

13. Evidence-Based Medicine Working Group. User's guide to the medical literature: VIII. How to use clinical practice guidelines. B. What are the recommendations and will they help me in caring for my patients? JAMA 1995; 274(20):1630-2.

14. Evidence-Based Medicine Working Group. User's guide to the medical literature: IX. A method for grading health care recommendations. JAMA 1995; 274(22):1800-4.

15. Evidence-Based Medicine Working Group. User's guide to the medical literature: X. How to use an article reporting variations in the outcomes of health services. JAMA 1996; 275(7):554-8.

16. Guyatt GH, Rennie D (editorial). User's guide to the medical literature. JAMA 1993; 270(17):2096-7.

17. Greenhalgh T, Naylor T. Papers that go beyond numbers (qualitative research). BMJ 1997; 315(7110):740-3.
18. Greenhalgh T. Papers that summarise other papers (systematic reviews and meta-analyses). BMJ,1997; 315(7109):672-5.

19. Greenhalgh T. How to read a paper. Papers that tell you what things cost (economic analyses). BMJ 1997; 315(7108):596-9.

20. Greenhalgh T. How to read a paper. Papers that report diagnostic or screening tests. BMJ 1997; 315(7107):540-3.

21. Greenhalgh T. How to read a paper. Papers that report drug trials. BMJ 1997; 315(7106):480-3.

22. Greenhalgh T. How to read a paper. Statistics for the nonstatistician. II: "Significant" relations and their pitfalls. BMJ. 1997; 315(7105):422-5.

23. Greenhalgh T. How to read a paper. Statistics for the nonstatistician. I: Different types of data need different statistical tests. BMJ 1997; 315(7104):364-6.

24. Greenhalgh T. Assessing the methodological quality of published papers. BMJ 1997; 315(7103):305-8.

25. Greenhalgh T. How to read a paper. Getting your bearings (deciding what the paper is about). BMJ 1997; 315(7102):243-6.

26. Greenhalgh T. How to read a paper. The Medline database. BMJ 1997; 315(7101):180-3.

27. Lowe HJ, Barnett GO. Understanding and using the medical subject headings $(\mathrm{MeSH})$ vocabulary to perform literature searches. JAMA 1994; 271(14):1103-8.

28. Castro AA, Clark OAC, Atallah AN. Optimal search strategy for clinical trials in the Latin American and Caribbean Health Science Literature. São Paulo Med J 1997; 115(3):1423-6. 